\title{
An experimental and numerical examination on the thermal inertia of a cylindrical lithium-ion power battery
}

\author{
Shixue Wang ${ }^{1}$, Kaixiang $\mathrm{Li}^{1}$, Yuan Tian ${ }^{2, *}$, Junyao Wang ${ }^{1}$, Yukang $\mathrm{Wu}^{1}$, Shan $\mathrm{Ji}^{1}$ \\ ${ }^{1}$ Key Laboratory of Efficient Utilization of Low and Medium Grade Energy (Tianjin University), \\ Ministry of Education, Tianjin 300072, China \\ ${ }^{2}$ Institute of Energy and Sustainable Development, School of Engineering and Sustainable \\ Development, De Montfort University, Leicester LE1 9BH, UK
}

\begin{abstract}
:
Thermal issues are increasingly critical for the scaling-up and integrated deployment of lithium-ion batteries (LIBs). To make battery temperature control more accurate, a concept of thermal inertia was proposed to cylindrical power batteries in the current study. Experimental results showed that the thermal inertia of the battery can greatly affect the thermal behavior during battery discharging process, based on which a battery thermal model was created by COMSOL Multiphysics with infrared imaging technology adopted to experimentally investigate the thermal inertia for a $\mathrm{LiFePO}_{4}$ (LFP) battery. It is evidenced that the model and the corresponding simulation can provide helpful guidance for the thermal behavior control and improve thermal performance. Furthermore, the temperature distribution and variation of the slack period (after discharge) were studied, including internal temperature, surface temperature and temperature difference. Results showed that the battery radius (R) and discharge rate (C) were the major factors that influenced the thermal inertia. In addition, a thermal inertial calculation model was proposed for predicting battery thermal inertia under different operating conditions.
\end{abstract}

Keywords: Cylindrical lithium-ion power battery; Thermal inertia; Temperature distribution; Infrared imaging

\section{Nomenclature}

\begin{tabular}{|c|c|c|c|}
\hline$A$ & Surface area $\left(\mathrm{m}^{2}\right)$ & $\mathrm{T}_{\mathrm{s}}$ & The highest temperature at slack period $\left({ }^{\circ} \mathrm{C}\right)$ \\
\hline$\alpha_{a}, \alpha_{c}$ & Oxidation/reduction coefficient & $\mathrm{t}$ & Process time (s) \\
\hline C & Discharge rate & $U$ & Open-circuit voltage (V) \\
\hline c & Lithium ion concentration $\left(\mathrm{mol} \mathrm{m}^{-3}\right)$ & $V$ & Voltage (V) \\
\hline$c_{p}$ & Specific heat capacity $\left(\mathrm{J} \mathrm{kg}^{-1} \mathrm{~K}^{-1}\right)$ & $\mathrm{v}$ & Volume $\left(\mathrm{m}^{3}\right)$ \\
\hline$c_{s, \max }$ & $\begin{array}{l}\text { Maximum lithium ion concentration } \\
\left(\mathrm{mol} \mathrm{m}^{-3}\right)\end{array}$ & $\mathrm{W}$ & Cell with (mm) \\
\hline$c_{e}$ & $\begin{array}{l}\text { Initial electrolyte concentration (mol } \\
\mathrm{cm}^{-3} \text { ) }\end{array}$ & \multicolumn{2}{|c|}{ Greek letters } \\
\hline$D$ & Diffusion coefficient $\left(\mathrm{m}^{2} \mathrm{~s}-1\right)$ & $\varepsilon$ & Porosity \\
\hline$E_{\text {act }}^{D e}$ & Activation energy-electrolyte lithium & $\eta$ & Overpotential (V) \\
\hline
\end{tabular}




\begin{tabular}{|c|c|c|c|}
\hline & ion diffusion $\left(\mathrm{J} \mathrm{mol}^{-1}\right)$ & & \\
\hline$E_{\mathrm{act}}^{i_{0}}$ & $\begin{array}{l}\text { Activation energy- exchange current } \\
\text { density }\left(\mathrm{J} \mathrm{mol}^{-1}\right)\end{array}$ & $\kappa$ & Ionic conductivity $\left(\mathrm{S} \mathrm{m}^{-1}\right)$ \\
\hline$E_{\mathrm{act}}^{i_{0}}$ & $\begin{array}{l}\text { Activation energy- solid phase lithium } \\
\text { ion diffusion }\left(\mathrm{J} \mathrm{mol}^{-1}\right)\end{array}$ & $\lambda$ & Thermal conductivity ( $\left.\mathrm{W} \mathrm{m}^{-1} \mathrm{~K}\right)$ \\
\hline$F$ & Faraday constant $\left(\mathrm{C} \mathrm{mol}{ }^{-1}\right)$ & $\rho$ & Density $\left(\mathrm{kg} \mathrm{m}^{-3}\right)$ \\
\hline$H_{a}$ & Humidity (\%) & $\sigma$ & Electronic conductivity $\left(\mathrm{S} \mathrm{m}^{-1}\right)$ \\
\hline $\mathrm{H}$ & Cell height (mm) & $\varphi$ & Potential (V) \\
\hline$h$ & $\begin{array}{l}\text { Equivalent convection heat transfer } \\
\text { coefficient }\left(\mathrm{Wm}^{-2} \mathrm{~K}^{-1}\right)\end{array}$ & \multicolumn{2}{|c|}{ Superscripts and Subscripts } \\
\hline$I$ & Current load (A) & 0 & Initial value \\
\hline$L$ & Thickness (m) & e & Liquid electrolyte \\
\hline Le & The thickness of the electrode (m) & eff & Effective values \\
\hline$P$ & Bruggeman factor & neg & Negative electrode \\
\hline $\mathrm{Q}_{1}$ & Total heat (J) & pos & Positive electrode \\
\hline$q$ & Quantity of heat (J) & s & Solid phase \\
\hline$R$ & Radius (m) & sep & Separator \\
\hline$r$ & Resistance $(\Omega)$ & r & Radius direction \\
\hline $\mathrm{T}$ & Temperature (K) & $\varphi$ & Circumferential direction \\
\hline $\mathrm{T}_{\mathrm{amb}}$ & Ambient temperature (K) & $\mathrm{z}$ & Axial direction \\
\hline $\mathrm{T}_{\text {sur }}$ & Surface temperature(K) & re & reaction heat \\
\hline$t_{+}{ }^{0}$ & Lithium-ion transfer coefficient & $o$ & ohmic heat \\
\hline$T_{\text {inc }}$ & Maximum temperature rise $\left({ }^{\circ} \mathrm{C}\right)$ & $i$ & Ion migration heat \\
\hline$\Delta T_{\max }$ & $\begin{array}{l}\text { Maximum temperature Difference } \\
\left({ }^{\circ} \mathrm{C}\right)\end{array}$ & ir & irreversible heat \\
\hline$T_{\text {ine }}$ & Maximum thermal inertia $\left({ }^{\circ} \mathrm{C}\right)$ & $c$ & contact resistance heat \\
\hline $\mathrm{T}_{\mathrm{h}}$ & The highest temperature $\left({ }^{\circ} \mathrm{C}\right)$ & Acronyn & \\
\hline $\mathrm{T}_{1}$ & The lowest temperature $\left({ }^{\circ} \mathrm{C}\right)$ & $\mathrm{CC}-\mathrm{CV}$ & Constant Current-Constant Voltage \\
\hline \multirow[t]{5}{*}{$\mathrm{T}_{\mathrm{t}}$} & $\begin{array}{l}\text { The temperature at discharge } \\
\text { termination }\left({ }^{\circ} \mathrm{C}\right)\end{array}$ & EVs & Electric Vehicles \\
\hline & & IC & Internal Combustion \\
\hline & & IR & Infrared Radiation \\
\hline & & LFP & $\mathrm{LiFePO}_{4}$ \\
\hline & & LIBs & lithium-ion Batteries \\
\hline
\end{tabular}

\section{Introduction}

In recent years, electric vehicles (EVs) have become increasingly popular as a solution to problems such as environmental pollution and fossil fuel depletion. EVs use lithium-ion batteries (LIBs) as energy-storage devices because they offer the advantages of stable working voltage, high power and energy density [1]. However, LIBs still suffer from problems such as overheating and large 
temperature variance during charging and discharging [2,3]. Thermal issues are increasingly critical for the scaling-up and integrated deployment of lithium-ion batteries. Such thermal issues in LIBs have limited the development of EVs. Under high current discharge rates, the internal and surface (i.e. external) temperatures of LIBs differ vastly: the former increases rapidly, whereas the latter increases slowly with a certain extent of lag due to the slow heat transfer process, which is called the thermal inertia phenomenon of the battery. When batteries are integrated into parallel or serial connections for a battery pack, their thermal inertia will increase significantly. The thermal inertia of a single cell serves as an important basis for thermal design and thermal management. If the influence of thermal inertia is ignored, batteries may suffer a high potential risk of thermal runaway caused by thermal inertia. Therefore, the knowledge of the thermal inertia behavior is helpful for optimization of battery thermal design.

A large number of studies were conducted to investigate the thermal behavior of batteries to solve their thermal problems and improve associated safety performance. An electrochemical-thermal numerical simulation based on the thermal equilibrium model was an ideal approach to reveal the mechanism underlying the temperature distribution, to evaluate the thermal safety of battery and to refine the thermal design [4-8]. To improve the accuracy of numerical models, previous studies mainly focused on the multi-physical (electrochemical-thermal) models [9-13] when investigating the battery thermal characteristics. These multi-physical models were used to study the distribution and the evolution of the temperature, ion concentration, current density and potential under different experimental conditions. Panchal et al. [14-15] presented a mathematical model to predict the transient temperature and voltage distributions of 18650 cylindrical lithium-ion battery at different discharge rates. Results showed that the increased C-rates could result in increased temperature on the principal surface of the battery. They recently studied the heat flux distributions on a prismatic lithium-ion battery at 1-4C discharge rates under various operating temperatures and boundary conditions [16], and provided significant quantitative data on the thermal behavior of lithium-ion batteries. Wu et al. [17] and Li et al. [18] established different heat effect models, which indicated that under high-temperature conditions, the cycle capacity and the lifespan of LIBs would be significantly deteriorated. Kim et al. [19] developed a thermal model to study the effect of the electrode configuration on the thermal behaviors of a lithium-polymer battery. Their results indicated that the current collecting tabs have a significant impact on the thermal behaviors of the battery. Dong [20] developed a numerical model for predicting the thermal behaviors of the lithium-ion battery. It was indicated that the increase in the temperature rising during the discharging process is higher than that during the charging process. In addition, it was found that the thermal behaviors were closely affected by the entropy change. Niculuţa et al. [21] conducted theoretical experimental and numerical studies to investigate the electro-thermal characteristics of lithium iron phosphate $\left(\mathrm{LiFePO}_{4}\right)$ battery cells. Results revealed that the central cells in the pack had the highest risk of overheating due to the maximum temperature and the lowest thermal dissipation rate in the central area. Xu et al. [22] studied the temperature distribution and heat generation properties of LIBs and optimized their thermal design through analytical solutions. 
Thermal inertia, commonly used for modelling heat transfer, is a material property related to thermal conductivity and volumetric heat capacity, which is a measure of the thermal mass and the heat flux rate which controls the surface temperature of a material. In the research field of heat transfer, a higher value of the thermal inertia means a longer time for the system to reach equilibrium. In fact, thermal inertia is applied in many aspects of engineering and meteorological fields. The thermal inertia of oceans is a major factor influencing climate change [23]. Taking advantage of the thermal inertia of a building to shift the cooling load is an important strategy for commercial buildings [24]. Utilizing the thermal inertia of a district heating network for thermal storage is considered an effective energy-saving method for improving the operational flexibility of combined heat and power [25]. In traditional internal combustion engine-powered vehicles, most cooling pumps are always designed with an off-delay function to overcome the thermal inertia of engine block. The thermal inertia in EV power batteries will have an even stronger impact on the BTMS design and control strategy.

In the current study, the concept of thermal inertia was introduced to cylindrical power batteries for the first time. The thermal inertia of a cylindrical LIB was increasingly critical for their scaling-up and integrated deployment. However, few studies have investigated the thermal inertia as an important basis for the thermal management of battery. The thermal behavior and temperature distribution of a battery are both affected by thermal inertia, which can significantly affect the thermal management. Existing studies on electrochemical thermal models focused on the thermal behavior of batteries during charging and discharging; however, they have not examined the heat conduction process of the slack periods. They either completely ignored or extremely simplified the thermal inertia of a battery pack, and therefore could not predict the accurate temperature change after discharging. Thus, a thermal model for thermal inertia of a cylindrical LIB was created and executed in COMSOL Multiphysics, with both experiments and simulations conducted to analyze the effects of discharge rate $\mathrm{C}$ and battery size $\mathrm{R}$ on thermal inertia. At the same time, a model for thermal inertia prediction was proposed, providing guidance for further design optimization of a LIB thermal management system.

\section{Experimental setup}

\subsection{Experimental system}

Fig. 1 is a schematic diagram of the thermal inertia experiment system. The charge and discharge cycles were regulated by the battery testing system controlled by a built-in programmable software, with current, voltage and resistance data collected. In the current study, the industrial infrared imager was used to measure the thermal performance of the battery cell in the charge/discharge processes, while the T-type thermocouples were used to calibrate the temperature measurement from IR. The measured temperature difference between the infrared imager and the thermocouples has a maximum tolerance of $0.1{ }^{\circ} \mathrm{C}$ allowed. It was noted that the ambient light contains infrared ray which may form a reflection on the batteries surface to affect the measurement error of the infrared imager. Therefore, to eliminate such effects, a light shade was applied to block the infrared ray of the ambient light, as shown in Fig. 1 As a result, the maximum measurement error by the infrared imager was less than $0.1{ }^{\circ} \mathrm{C}$. The infrared imager was fixed on a tripod and 0.6 meters from the surface of the battery cell and the lens, 
which was perpendicular to the measured surface.

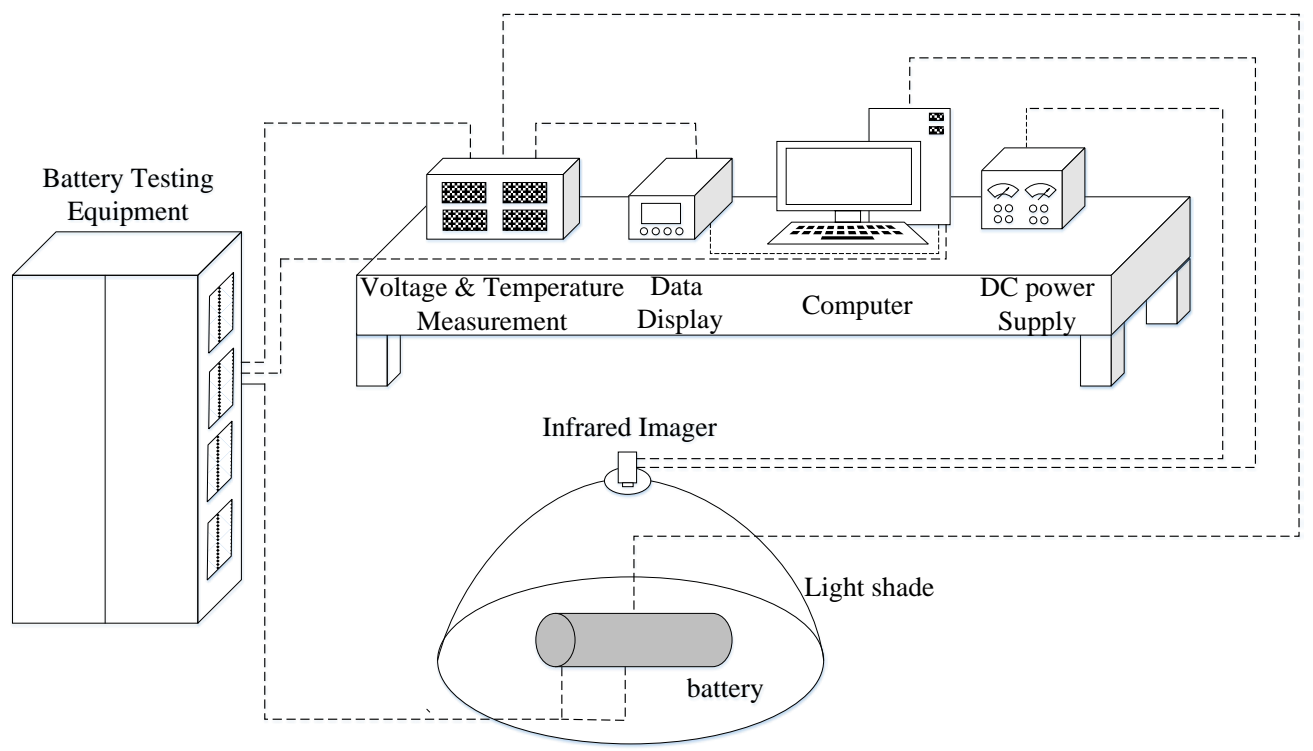

(a) experimental schematic

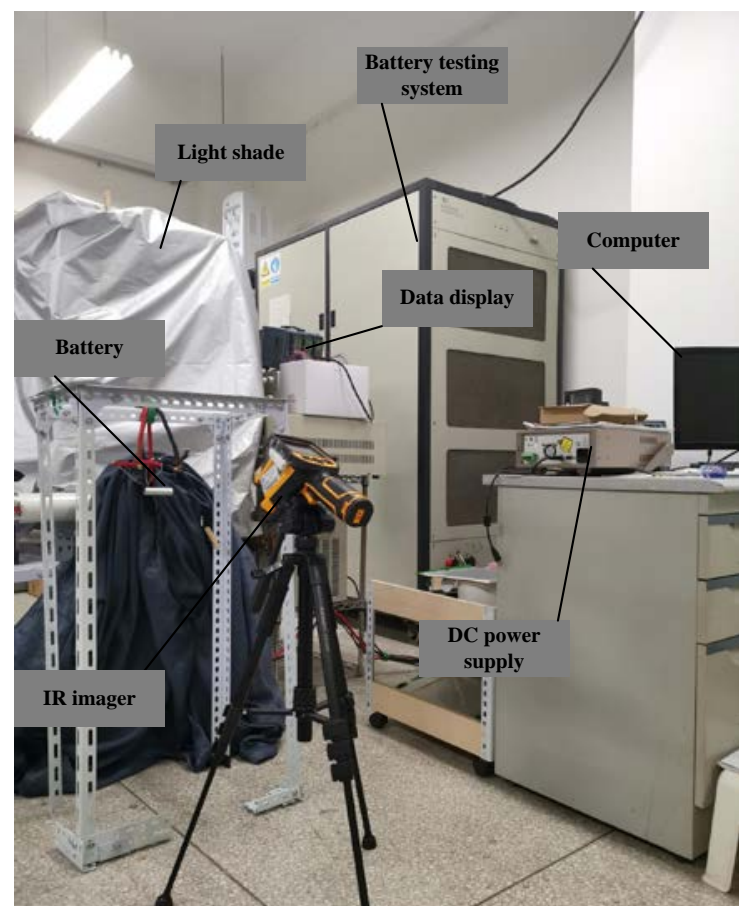

(b) experimental setup

Fig. 1. The experiment system.

Table 1. Battery cell parameters

\begin{tabular}{cccc}
\hline Items & Parameters & Items & Parameters \\
\hline Cell with (W) & $18 \mathrm{~mm}$ & Weight & $42 \mathrm{~g}$ \\
Cell height (H) & $65 \mathrm{~mm}$ & Internal resistance & $30 \mathrm{~m} \Omega$ \\
Rated capacity & $1100 \mathrm{mAh}$ & Max continuous discharge rate & $40 \mathrm{C}$ \\
Rated voltage & $3.2 \mathrm{~V}$ & Discharge cut-off voltage & $2.0 \mathrm{~V}$ \\
Charge cut-off & $3.65 \mathrm{~V}$ & & \\
voltage & & & \\
\hline
\end{tabular}


An LFP 18650 battery was used in the current study, with rated capacity of 1.1 Ah and rated voltage of $3.2 \mathrm{~V}$, as shown in Table 1 . The battery was fixed by adiabatic plastic clamps at the edges to ensure that the battery surface was only exposed to air and not touched by any other experimental components.

\subsection{Experimental procedures}

This study aims to investigate the thermal behavior of the LIB. Therefore, the ambient temperature should be consistent during the experimental process. The ambient temperature was maintained at $25 \pm 0.5^{\circ} \mathrm{C}$ with a maximum variation of $1{ }^{\circ} \mathrm{C}$. The battery temperature was measured under different charge/discharge rates with a cut-off voltage of $2.00 \mathrm{~V}$. Specifically, the charging process follows the standard CC-CV method, in which a battery was initially charged at a constant current of $0.5 \mathrm{C}$ until the voltage reaches $3.65 \mathrm{~V}$ (charge and discharge rates of a battery are governed by C-rates; the capacity of a battery is commonly rated at $1 \mathrm{C}$, meaning that a fully charged battery rated at $1 \mathrm{Ah}$ should provide $1 \mathrm{~A}$ for one hour), and then charged at a constant voltage mode. Then, the charging process was ended when the charging current drops to less than 0.05 C. Table 2 lists the parameters of IR imager, which was well calibrated and applied to measure the battery temperature in both charging and discharging processes. The temperature distribution can be acquired by the infrared imager with high accuracy and resolution since there was no physical contact and the influence of the ambient was eliminated by the shield in the experiment.

Table 2. Infrared imager parameters.

\begin{tabular}{cccc}
\hline Items & Parameter & Items & Parameter \\
\hline Ambient temperature $\mathrm{T}_{\mathrm{amb}}$ & $25^{\circ} \mathrm{C}$ & Thermal infrared emissivity & 0.60 \\
Ambient humidity $\mathrm{H}_{\mathrm{a}}$ & $55 \%$ & Measuring distance & 0.6 meter \\
\hline
\end{tabular}

Measurement error of infrared imager was restricted by the following aspects (1)degree of accuracy, T-type thermocouples were calibrated by ice water mixture in a vacuum bottle to ensure the difference between the measured value and the real temperature was no more than $0.1^{\circ} \mathrm{C} ;(2)$ degree of precision, the measured temperature difference between the infrared imager and the thermocouples was allowed to be no more than $0.1^{\circ} \mathrm{C}$ during the experiments by adjusting battery surface emissivity; (3) repeatability, at room temperature $\left(25^{\circ} \mathrm{C}\right)$, the surface temperature of the battery was measured several times, the measured temperature difference between the infrared imager and the thermocouples was no more than $0.1{ }^{\circ} \mathrm{C}$; (4) reproducibility, at $50{ }^{\circ} \mathrm{C}$ high-temperature test chamber, the surface temperature of the battery was measured several times, the measured temperature difference between the infrared imager and the thermocouples is no more than $0.1{ }^{\circ} \mathrm{C}$.

\subsection{Key parameters}

The maximum temperature increase $\left(T_{i n c}\right)$ represents the temperature difference between the highest temperature $\left(T_{h}\right)$ and the ambient temperature $\left(T_{a m b}\right)$ of the battery cell, which is defined and calculated by Eq. (1):

$$
T_{\text {inc }}=T_{h}-T_{a m b}
$$


The maximum temperature difference $\left(\Delta T_{\max }\right)$ denotes the temperature difference between $T_{\mathrm{h}}$ and the lowest temperature $\mathrm{T}_{1}$, as shown in Eq. (2),

$$
\Delta T_{\max }=T_{h}-T_{l}
$$

The maximum thermal inertia $\left(T_{\text {ine }}\right)$ denotes the temperature difference between discharge termination temperature $T_{t}$ and the highest temperature of the slack period $T_{S}$, as shown in Eq. (3),

$$
T_{\text {ine }}=T_{t}-T_{s}
$$

\subsection{Electrochemical thermocouple mode}

The 18650 cylindrical LIBs were formed by winding a multilayer of cathode, electrolyte, separator, anode, collectors and other supporting materials. To study its thermal performance during discharging, Fang [26] and Lee [27] simplified the cylinder's helical structure to a single-layer structure for the convenience of numerical calculations, as shown in Fig.3. The two-dimensional geometric model of the battery was divided into three areas: nylon axis, active material and stainless-steel shell, with the thickness of each layer being $2 \mathrm{~mm}, 0.25 \mathrm{~mm}$ and $6.75 \mathrm{~mm}$, respectively. The rectangular grid was used for battery mesh model and calculation, a total of 1632 cells were generated in three areas, with the maximum cell size of $6.5 \times 10^{-6} \mathrm{~m}$ and the minimum cell size of $1.3 \times 10^{-6} \mathrm{~m}$. Such a structure assumed that the current density distribution on the electrode was uniform. In fact, during internal particle transfer in the battery, generate/dissipate processes are all completed within a single narrow tunnel. Also, according to this method, the research object will approximately be treated as the single narrow tunnel batteries, in the thickness direction from left to right of single batteries macro physical structure was the anode active material, the separator and the cathode active material, as shown in Fig.2. The following assumptions were made about the battery: (1) The battery material was evenly distributed and its density was consistent; the quality and volume change of the battery during charging and discharging were ignored. (2) Owing to the minor internal liquidity of the battery, internal convection heat transfer was safely neglected. (3) Radiation dissipation was ignored due to the temperature variation range was limited. (4) The thermal properties of the battery did not change with temperature and SOC.

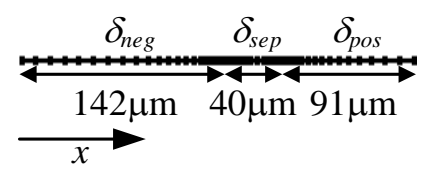

Fig. 2 One-dimensional electrochemical model 

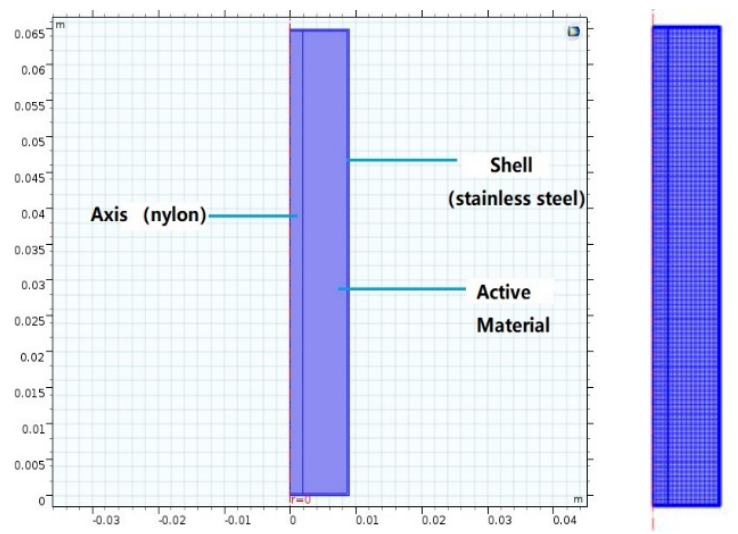

Fig. 3 Two-dimensional physical and mesh model.

In the process of battery discharge, the positively charged lithium ions are diffused to the surface of LixC $_{6}$, which constituted the solid phase of the negative electrode, and electrochemical reactions are carried out to generate a liquid or colloidal electrolyte solution. Lithium-ion diffused through the electrolyte solution to the anode. It moves into the solid phase region through an electrochemical reaction, which contains the particles of positive electrode active material. Due to electronic insulation in the porous diaphragm. forcing the electrons to move according to the circuit or the opposite direction of load. The thermal model was set up according to the principle of electrolyte and solid-phase electrode electron and charge conservation. The control equation and boundary conditions of the battery electrochemical - thermal model are summarised in Table 3.

Table 3 Control equation and boundary conditions of the battery electrochemical -thermal model [28]

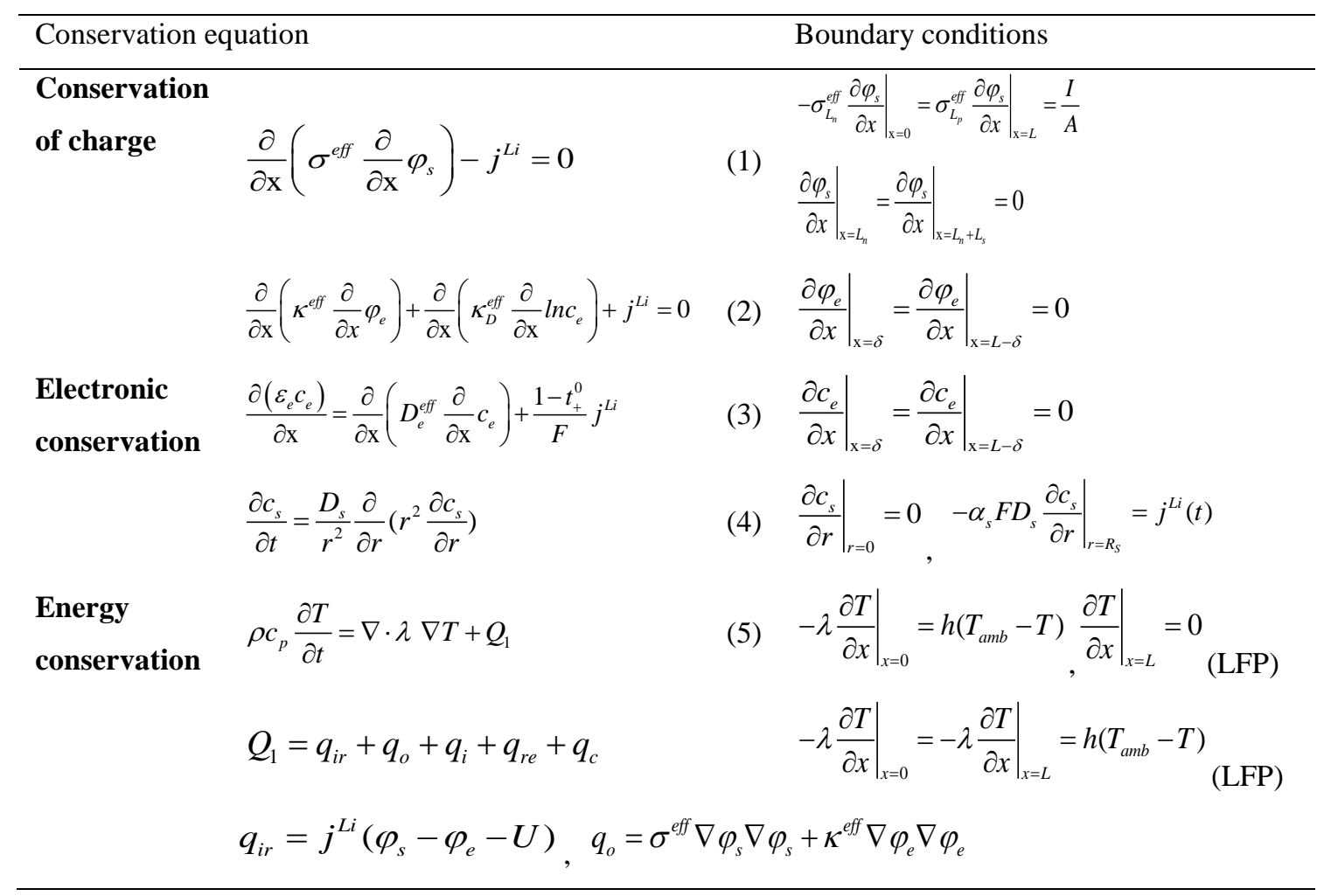




$$
q_{i}=\kappa_{D}{ }^{e f f} \nabla \ln c_{e} \nabla \varphi_{e}, \quad q_{r e}=j^{L i}\left(T \frac{\partial U}{\partial T}\right), \quad q_{c}=\frac{I^{2} R_{c}}{A v}
$$

$\mathrm{Q}_{1}$ in Table 3 represents all the quantity of heat generation and heat dissipation during the discharge process, including the irreversible electrochemical reaction heat $q_{\mathrm{re}}$, ohmic heat $q_{\mathrm{o}}$, ion migration heat $q_{\mathrm{i}}$, irreversible heat $q_{\text {ir }}$ and contact resistance heat $q_{\mathrm{c}}$. In order to quantify the intensity of electrochemical reaction during high discharge rates of the battery, the Butler-Volmer equation was introduced to calculate the transport current density of the whole battery:

$$
j^{L i}=a_{s} i_{0}\left[\exp \left(\frac{a_{a} F}{R T} \eta\right)-\exp \left(\frac{-a_{c} F}{R T} \eta\right)\right]
$$

where $i_{0}$ is the exchange current density, $a_{a}$ and $a_{c}$ are transfer coefficients, $\eta$ denotes the local surface overpotential and $F$ is the Faraday constant.

The electrochemical-thermal model parameters of the lithium-ion batteries model are shown in Table 4, The parameters of a cylindrical 18650 battery are collected from the literature [29,30] and COMSOL Multiphysics user guide [31].

\begin{tabular}{|c|c|c|c|}
\hline & Cathode & Separator & Anode \\
\hline Materials & $\mathrm{LiFePO}_{4}$ & Polyolefin & $\mathrm{LiC}_{6}$ \\
\hline Thickness, $L(\mathrm{~cm})$ & $142 \times 10^{-4}$ & $40 \times 10^{-4}$ & $91 \times 10^{-4}$ \\
\hline Thermal conductivity, $\lambda\left(\mathrm{W} \mathrm{m}^{-1} \mathrm{~K}^{-1}\right)$ & 0.4 & 0.5 & 0.4 \\
\hline Porosity, $\varepsilon$ & 0.59 & 0.42 & 0.54 \\
\hline Ionic radius, $r(\mu \mathrm{m})$ & 5 & N/A & 5 \\
\hline Maximum lithium ion concentration, $c_{s, \max }\left(\mathrm{mol} \mathrm{m}^{-3}\right)$ & 31000 & N/A & 51800 \\
\hline Initial electrolyte concentration, $c_{e}\left(\mathrm{~mol} \mathrm{~cm}^{-3}\right)$ & $1.2 \times 10^{-3}$ & $1.2 \times 10^{-3}$ & $1.2 \times 10^{-3}$ \\
\hline Solid phase conductivity, $\sigma\left(\mathrm{S} \mathrm{m}^{-1}\right)$ & 1.0 & N/A & 0.1 \\
\hline Solid phase lithium ion diffusion coefficient, $D_{s}\left(\mathrm{~m}^{2} \mathrm{~s}^{-1}\right)$ & $2.55 \times 10^{-10}$ & & $2.0 \times 10^{-10}$ \\
\hline $\begin{array}{l}\text { The diffusion coefficient of lithium ions in electrolytes } D_{e} \\
\qquad\left(\mathrm{~m}^{2} \mathrm{~s}^{-1}\right)\end{array}$ & $1.5 \times 10^{-10}$ & $1.5 \times 10^{-10}$ & $1.5 \times 10^{-10}$ \\
\hline $\begin{array}{l}\text { Activation energy } \\
\text { (electrolyte lithium ion diffusion), } E_{\text {act }}^{D e}\left(\mathrm{~J} \mathrm{~mol}^{-1}\right)\end{array}$ & 10000 & N/A & 10000 \\
\hline $\begin{array}{l}\text { Activation energy } \\
\text { (exchange current density), } E_{\text {act }}^{i_{0}}\left(\mathrm{~J} \mathrm{~mol}^{-1}\right)\end{array}$ & 30000 & N/A & 30000 \\
\hline $\begin{array}{c}\text { Activation energy } \\
\text { (solid phase lithium ion diffusion), } E_{\text {act }}^{D_{s}}\left(\mathrm{~J} \mathrm{~mol}^{-1}\right)\end{array}$ & 50000 & N/A & 25000 \\
\hline
\end{tabular}

Table 4: Model parameters for different areas of the battery [28-30]. 
The 18650 lithium-ion battery was composed of a variety of materials and formed with winding structure. The calculation of thermal conductivity in heat transfer was based on the theory of heat resistance, calculating the average thermal conductivity of the battery's radial, circumferential and axial direction respectively, and computation expression as:

$$
\begin{array}{r}
\lambda_{r}=\frac{r}{\sum \frac{\Delta r_{i}}{\lambda_{i}}} \\
\lambda_{\varphi}=\lambda_{z}=\sum \frac{\lambda_{i} \Delta r_{i}}{r}
\end{array}
$$

$\lambda_{r}, \lambda_{\varphi}$ and $\lambda_{z}$ are thermal conductivity $(\mathrm{W} /(\mathrm{m} \cdot \mathrm{K}))$ in the direction of $\mathrm{r}, \varphi$ and $\mathrm{z}$; $\mathrm{r}$ is radius(m) of the battery, $\Delta r_{i}$ is the thickness $(\mathrm{m})$ of each material in radial. $\lambda_{i}$ is thermal conductivity $(\mathrm{W} /(\mathrm{m} \cdot \mathrm{K}))$ of each material in the battery. The thermal conductivity can be obtained by calculation: $\lambda_{r}=1.4556 \mathrm{~W} /(\mathrm{m} \cdot \mathrm{K})$, $\lambda_{\varphi}=\lambda_{z}=116.0468 \mathrm{~W} /(\mathrm{m} \cdot \mathrm{K})$

The density of batteries $\rho$ and the specific heat capacity $c$ are generally approximated by the weighted average.

$$
\begin{gathered}
\rho=\frac{\sum m_{i}}{\sum v_{i}} \\
c=\frac{1}{m} \sum c_{i} m_{i}
\end{gathered}
$$

In the formula, $m_{i}, v_{i}, c_{i}$ are the mass, volume and specific heat of each component of the battery. Natural convection heat transfer coefficient $h=5 \mathrm{~W} /(\mathrm{m} \cdot \mathrm{K})$

\section{Results and discussions}

\section{1 model verification}

In order to verify the reliability of the battery model, the simulation voltage variation curve of $40 \mathrm{C}$ discharge was contrasted with the experimental voltage curve. As shown in Fig.4, the simulation results were almost consistent with the experimental results. The maximum error of the electrochemical model was $0.20 \mathrm{~V}$ and the average error was $0.12 \mathrm{~V}$. Meanwhile, the reliability of the electrochemical thermo-coupling model can be verified. The simulated surface temperature compared with the experimental temperature, the maximum error was $5.4{ }^{\circ} \mathrm{C}$, the average error was $3.11{ }^{\circ} \mathrm{C}$. The 
experimental results of the battery surface temperature shown in Fig.5 were generally consistent with the simulation results, thus verifying the correctness and reliability of the model. As shown in Table 5, the error was acceptable, indicating that the model can meet the requirements of subsequent calculation and analysis.

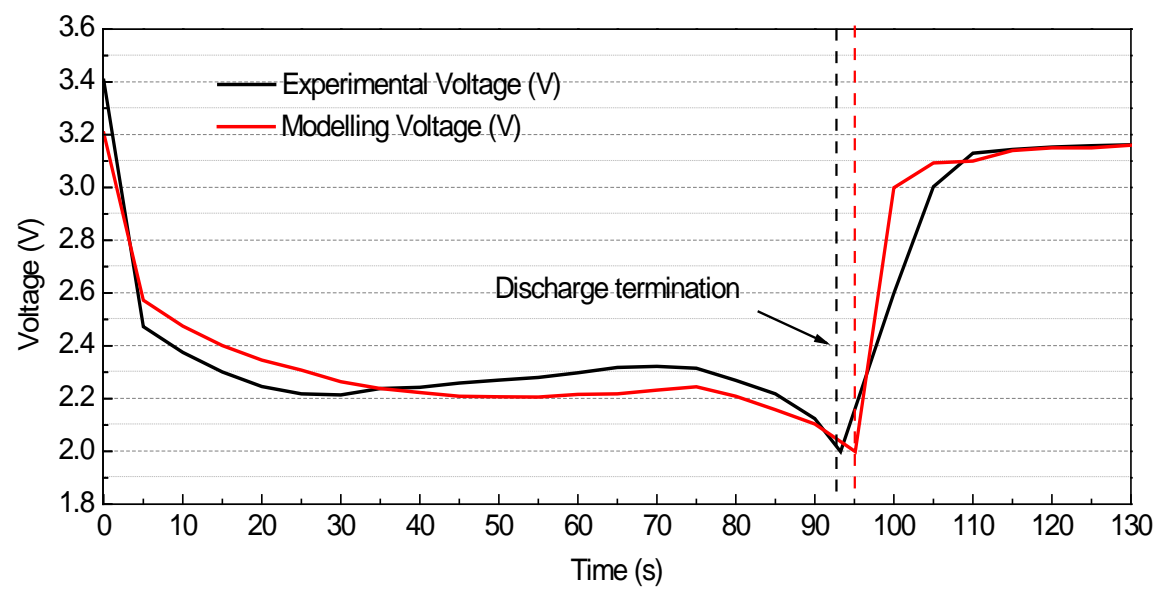

Fig.4 Battery voltage variation

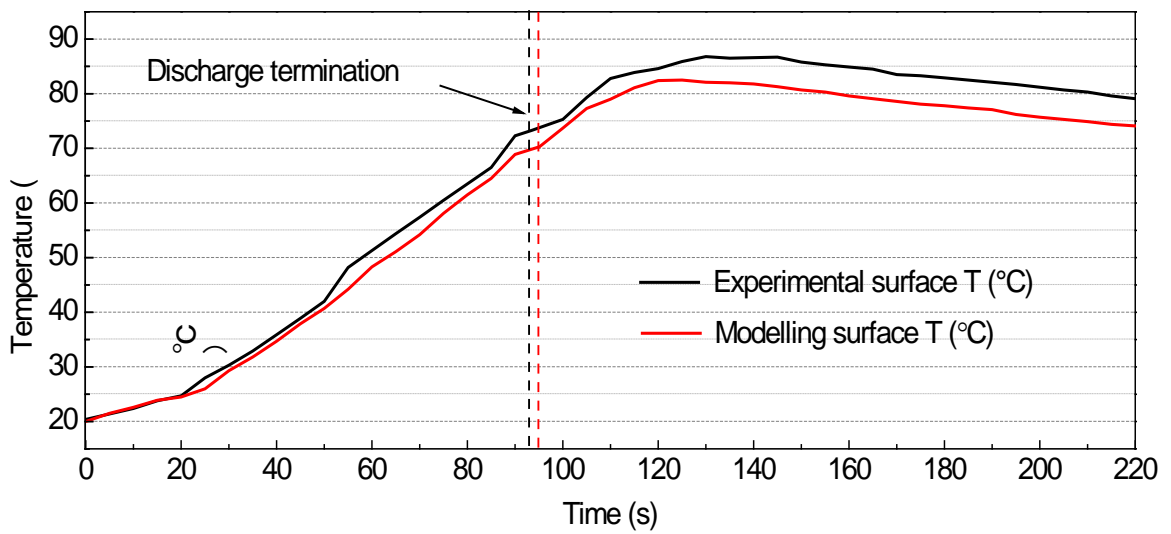

Fig. 5 Battery surface temperature

Table 5. Model error analysis

Electrochemical Model

Maximum error

Maximum relative error

Average error

Average relative error
$0.20 \mathrm{~V}$

$5.51 \%$

$0.12 \mathrm{~V}$

$2.07 \%$
Electrochemical-Thermal coupled Model.

Maximum error

$5.4^{\circ} \mathrm{C}$

Maximum relative error

$6.22 \%$

Average error

$3.11^{\circ} \mathrm{C}$

Average relative error
$4.51 \%$

\subsection{The influence of thermal inertia on the surface temperature of the battery}

The thermal inertia was mainly caused by the internal heat source and external temperature difference during the battery discharge process. After the discharge, the internal heat source was no longer in 
existence. Due to the presence of internal and external temperature difference, the heat conduction process continued, resulting in a further increase in the surface temperature difference of the battery. Then the battery surface exchanged heat with the surrounding air, and the surface temperature began to drop. In order to simplify the inertia model, two kinds of heat sources were neglected. After the discharge process, there was a certain amount of reaction heat in the process of restoring the equilibrium potential of the battery, this reaction heat was three to five orders of magnitude less than the reversible heat during the battery discharge (depending on the degree of polarization). Therefore, the reaction heat did not play the dominant role in affecting the battery temperature change. When the battery was in high temperature, the internal material began to decompose and produce heat. In this experiment, the battery temperature had not yet reached the temperature threshold of thermal abuse, so there was no side reaction occurred, which was safely ignored.

It was proved that the thermal inertia had a significant influence on the surface temperature of the battery, therefore a reference model was set up for comparison. The basic physical parameters of the control model were consistent with the inertial model. The initial temperature setting was set as follows: the initial temperature was the same as that of the inertia model; the temperature of each layer inside and outside the battery was consistent; the internal and surface were evenly distributed. As shown in Fig. 6, at the end of the $40 \mathrm{C}$ discharge, the temperature change trend in the unsteady uniform heat dissipation model (inertialess) was remarkedly different from that in the inertia model, with the maximum temperature difference rising to $15.1{ }^{\circ} \mathrm{C}$. As shown in Fig. 7, the increase in discharge rate affected the battery heat generation rate. When the heat generation rate was higher than the heat dissipation rate, then the heat starts to accumulate inside the battery. Under the condition of high discharge rate, due to the high heat production rate and short discharge time, the thermal inertia at 40C discharge can reach $12.1{ }^{\circ} \mathrm{C}$. It was pointed out that thermal inertia exists in the process of battery discharging and had a significant influence on the surface temperature of the battery. In the battery thermal management system, if the influence of thermal inertia was neglected, the temperature prediction of the battery would be significantly far from the true values, thus reducing the thermal management efficiency and causing battery deterioration. 


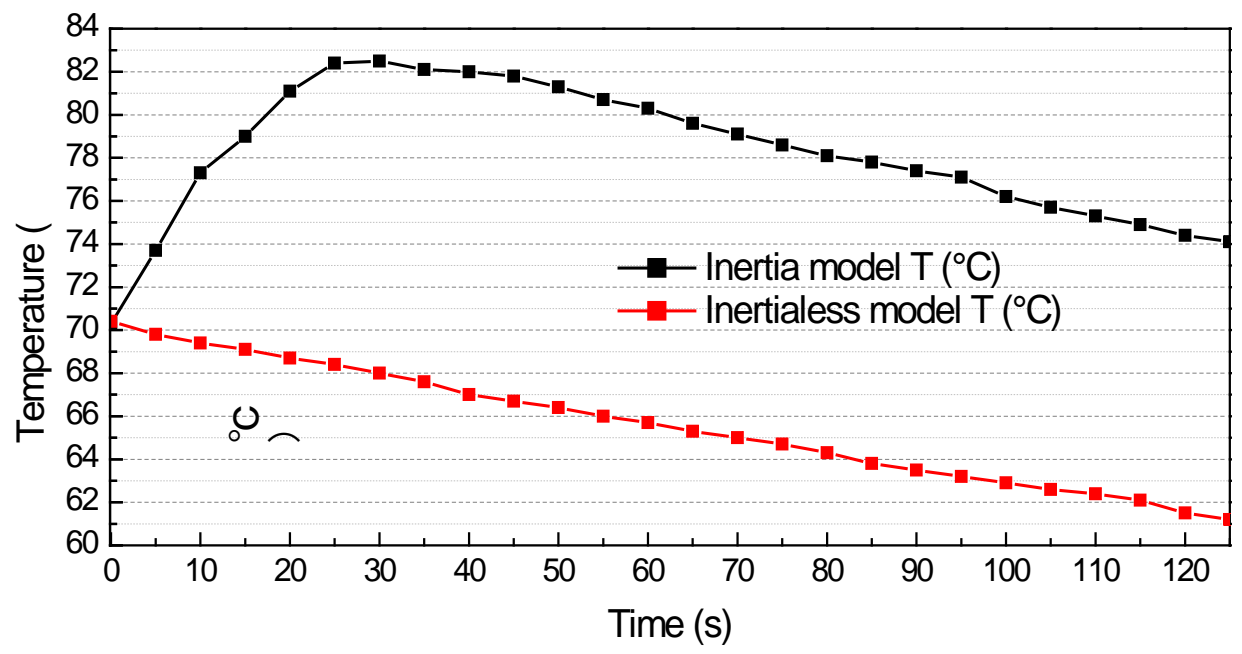

Fig. 6 Inertia and inertialess model (40 C)

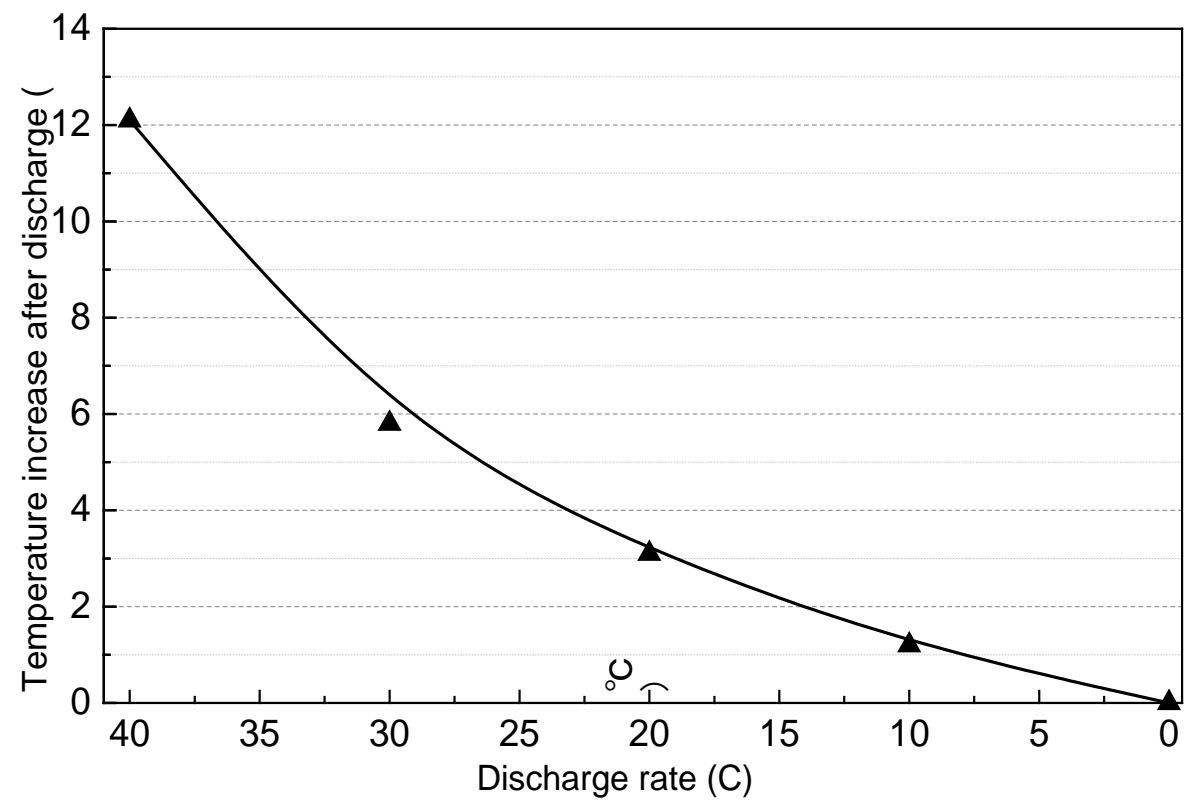

Fig. 7 Thermal inertia \& discharge rate

\subsection{The influence of battery radius $R$ on thermal inertia}

Fig. 8 shows the infrared images of the battery 40C discharge processes under DOD of 20\%, 40\%, $60 \%, 80 \%$ and the end of discharge, respectively. According to the experimental infrared imaging results, the axial line analysis of the surface of the battery shows that the temperature distribution of the cell surface was relatively uniform and the temperature gradient was small. As shown in Fig.9, through simulation studies battery slice isotherm distribution showed that the calculating results agreed with the experimental results, the axial temperature distribution of battery was small, and that the radial temperature gradient was larger than axial. Therefore, it can be inferred that the battery characteristic size $\mathrm{R}$ would have a great influence on the radial temperature gradient, thus affecting the change of the 
thermal inertia. Three models were established by using the 14650, 18650 and 26650 batteries, which were commonly used in commercial cylindrical lithium-ion batteries, with a diameter of $14 \mathrm{~mm}, 18 \mathrm{~mm}$ and $26 \mathrm{~mm}$, respectively. Under the condition that the nylon axis and the thickness of the steel shell were unchanged, experimental results during the 40C discharge showed that the radius size increased with the internal and external temperature difference at the moment of battery discharge termination. As shown in Fig. 10, the 14650, 18650 and 26650 temperature difference between the inside and outside of the battery at the end of the discharge time was $20.4{ }^{\circ} \mathrm{C}, 23.6{ }^{\circ} \mathrm{C}$ and $25.5{ }^{\circ} \mathrm{C}$ respectively. It can be inferred that the greater the radius of the coil cylinder, the greater the thermal inertia after the discharge.

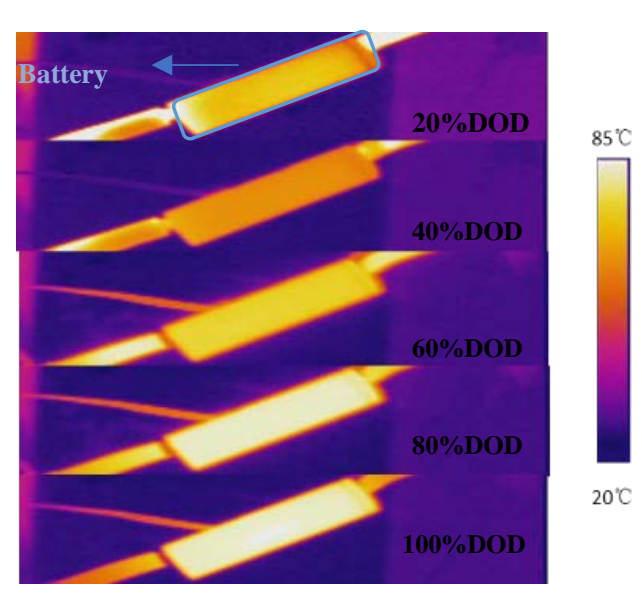

Fig. 8 IR imaging of battery surface temperature.

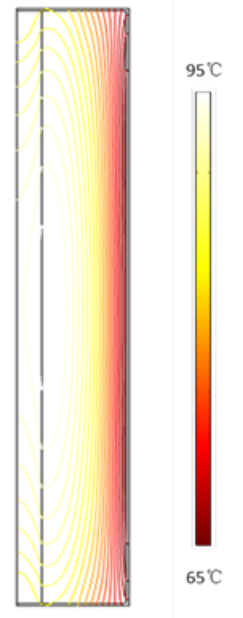

Fig. 9 Isothermal diagram

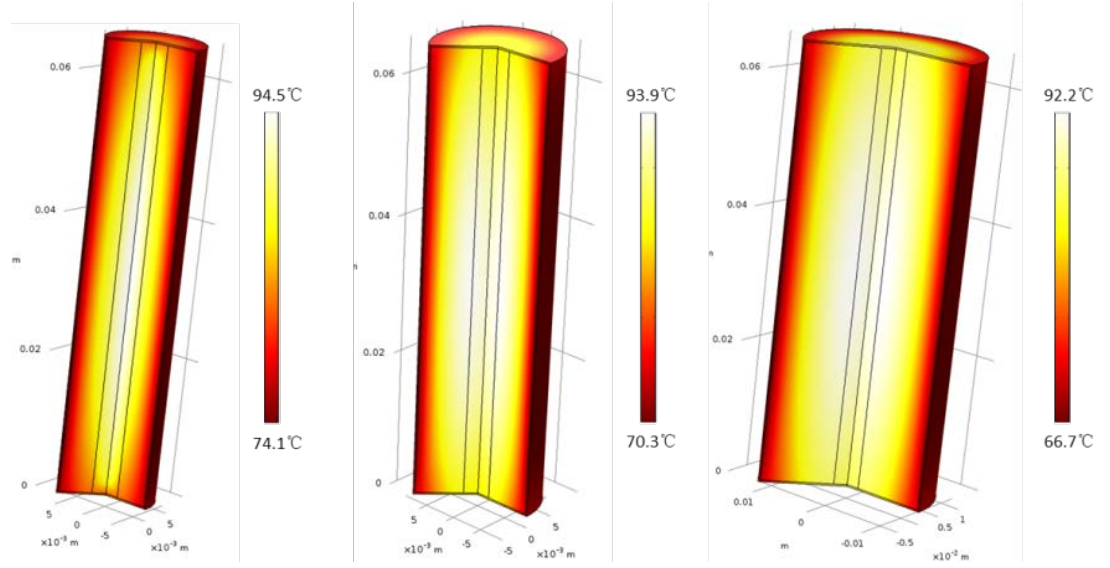

Fig. 10 14650,18650 and 26650 battery temperature distribution at the end of discharge.

\subsection{Thermal inertia calculation model of cylindrical batteries}

In order to estimate the thermal inertia of different characteristic sizes and working conditions, the current study presents a model of thermal inertia prediction for cylindrical batteries. The battery surface 
temperature rise $T_{\text {inc }}(Y)$ was defined as a dependent variable, with independent variables being the discharge rate $\mathrm{C}\left(\mathrm{X}_{1}\right)$, battery radius $\mathrm{R}\left(\mathrm{X}_{2}\right)$ and time $\mathrm{t}\left(\mathrm{X}_{3}\right)$. A multivariate linear regression analysis was performed on the existing data. The data scope was shown in Table 6.

Table 6. The range of the independent variable.

\begin{tabular}{llll} 
Independent variable & Discharge rate C $\left(\mathrm{X}_{1}\right)$ & Battery radius $\mathrm{R}\left(\mathrm{X}_{2}\right)$ & Time $\mathrm{t}\left(\mathrm{X}_{3}\right)$ \\
\hline Range & $10-40 \mathrm{C}$ & $7-13 \mathrm{~mm}$ & $0-120 \mathrm{~s}$ \\
\hline
\end{tabular}

The function form of the data was analyzed as $\mathrm{Y}=\mathrm{at}^{2}+\mathrm{bt}+\mathrm{c}+\mathrm{dX}_{1} \mathrm{eX}_{2} \mathrm{f}$ and the data was brought into the calculation to obtain the parameters of a, b, c, d, e and f. The parameter values and errors depicted in Table 7.

Table 7. Fitting parameters

\begin{tabular}{ccc}
\hline Parameters & Value & $\begin{array}{c}\text { Standard } \\
\text { error }\end{array}$ \\
\hline a & -2.48241 & 1.40711 \\
& $\times 10^{-4}$ & $\times 10^{-4}$ \\
& & \\
b & -0.00995 & 0.01748 \\
$\mathbf{c}$ & 42.4775 & 0.67373 \\
$\mathbf{d}$ & 0.03963 & 0.0131 \\
$\mathbf{e}$ & 2.01517 & 0.08659 \\
$\mathbf{f}$ & -0.33219 & 0.03572 \\
\hline
\end{tabular}

The best fitting can be expressed as:

$$
Y=-0.000248 X_{3}^{2}-0.00995 X_{3}+42.4775+0.03963 X_{1}^{2.01517} X_{2}{ }^{-0.33219}
$$

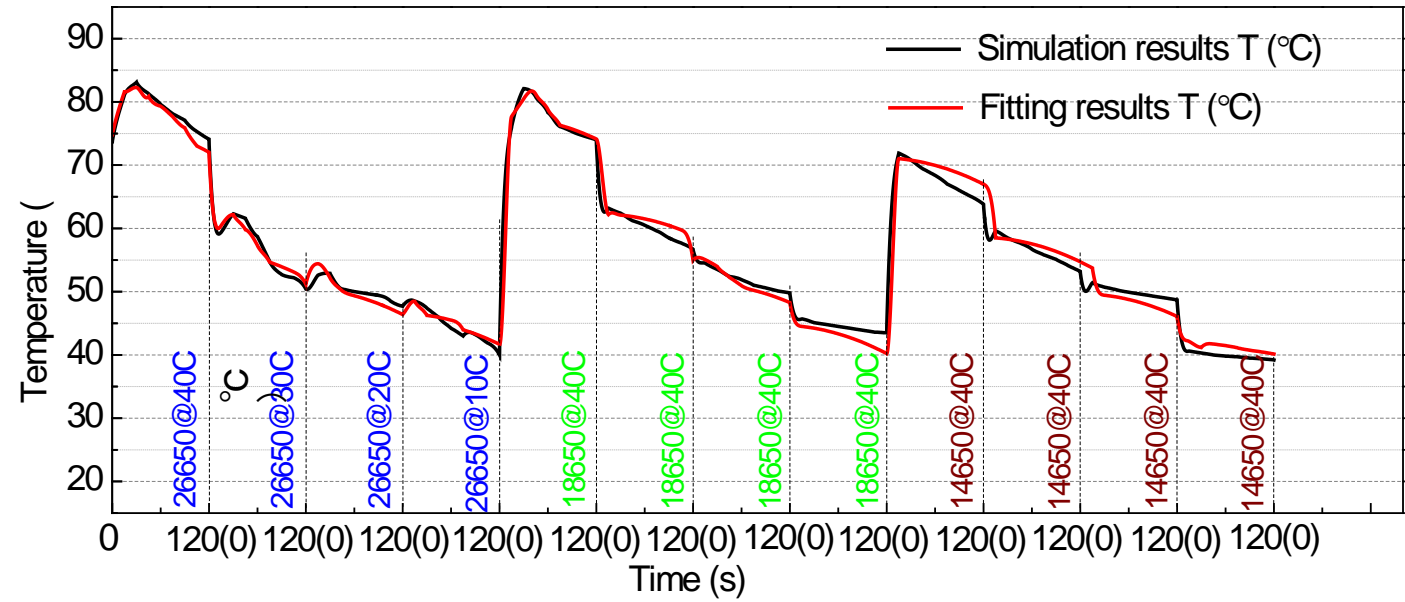


Fig. 11 The simulation and fitting results

As shown in Fig.11, the fitting result was consistent with the variation trend of the simulation results, and the average relative error was only 4.04\%. The accuracy and stability of the thermal inertial calculation model for cylindrical batteries were verified.

\section{Conclusion}

In the IC engine vehicles, most of cooling pumps were designed with function of off delay to overcome the thermal inertia of engine block. For the same reason, the thermal inertia in EV battery has a major impact on BTMS design and control strategy. The current study firstly introduced the concept of thermal inertia to cylindrical power batteries, with both the experiment and the simulation indicating that cylindrical LIBs presented evident thermal inertia. Due to the existence of thermal inertia, the LIB temperature increased continuously after discharge and may result in safety problems.-In addition, when batteries are used in series and parallel, the thermal inertia increased dramatically. The key effect factors such as battery discharge rate $(\mathrm{C})$ and radius $(\mathrm{R})$ on thermal inertia were investigated through experimental and simulation studies.to clarify the thermal inertia of cylindrical LIBs. The model provides an effective basis for describing the thermal characteristics of the battery and for designing a better and accurate thermal management system. An empirical model of cylindrical battery thermal inertia was also proposed, which can be used to estimate the cell surface temperature rise-at commonly used range of time, discharge rate and battery radius. Finally, the thermal inertia of cylindrical LIBs under different characteristic sizes and working conditions were summarized:

(1)-After a high-rate discharge, a cylindrical LIB showed slower change in surface temperature than in internal temperatmre, and therefore a large thermal inertia was formed. The maximum temperature difference between the thermal inertia model and the inertialess model was $15.1^{\circ} \mathrm{C}$ when discharge rate was higher than $40 \mathrm{C}$. Therefore, thermal inertia cannot be neglected in the thermal design of high-rate LIBs.

(2) For cylindrical batteries, the maximum temperature difference between the inside and outside of the battery showed a significant increase trend with the increase in the discharge rate. Due to the external temperature of the battery increased slowly, the thermal inertia also increased. 
(3) At the end of the discharge, temperature distribution inside the battery, and the temperature gradient existed mainly in the radial direction. while the axial and circumferential temperature gradient was negligible. Therefore, with an increase in the battery radius, the radial temperature difference of the battery would increase significantly, thus the temperature falling of battery after-discharge was hindered by the slow heat conduction, resulting in an increase in thermal inertia.

\section{Acknowledgments}

The work is supported by De Montfort University through its distinguished Vice-Chancellor 2020 Programme, UK Science and Technology Facilities Council (STFC) through Batteries Early Career Researcher Award and the Ministry of Science and Technology of China through the Programme of International Cooperation (2016YFE0118600).

\section{References}

[1] Zhao J, Rao Z, Huo Y, Liu X, Li Y. Thermal management of cylindrical power battery module for extending the life of new energy electric vehicles. Appl. Therm. Eng. 2015;85:33-43.

[2] An Z, Jia L, Wei L, Dang C, Peng Q. Investigation on lithium-ion battery electrochemical and thermal characteristic based on electrochemical-thermal coupled model. Appl. Therm. Eng. 2018;137:792-807

[3] Chen D, Jiang J, Kim GH, Yang C, Pesaran A. Comparison of different cooling methods for lithium ion battery cells. Appl. Therm. Eng. 2016;94:846-854.

[4] Kim US, Shin CB, Kim CS. Modelling for the scale-up of a lithium-ion polymer battery. J. Power Sources 2009;189(1):841-846.

[5] Chacko S, Chung YM. Thermal modelling of Li-ion polymer battery for electric vehicle drive cycles. J. Power Sources 2012;213(9):296-303.

[6] Inui Y, Kobayashi Y, Watanabe Y, Watase Y, Kitamura Y. Simulation of temperature distribution in cylindrical and prismatic lithium ion secondary batteries. Energ. Convers. Manage. 2007;48 (7):2103-2109.

[7] Huria T, Ceraolo M, Gazzarri J, Jackey R. High fidelity electrical model with thermal dependence for characterization and simulation of high power lithium battery cells. Electric Vehicle Conference IEEE 2012;1-8.

[8] Yi J, Kim US, Shin CB, Han T, Park S. Three-dimensional thermal modelling of a lithium-ion battery considering the combined effects of the electrical and thermal contact resistances between current collecting tab and lead wire. J. Electrochem. Soc. 2013;160(3): A437-A443.

[9] Griffiths WD. A model of the interfacial heat-transfer coefficient during unidirectional solidification of an aluminium alloy. Metall. Mater. Trans. B-Proc. Metall. Mater. Proc. Sci. 2000;31 (2):285-295.

[10] Guo M, White RE. A distributed thermal model for a Li-ion electrode plate pair. J. Power Sources 
2013;221(1):334-344.

[11]Lee KJ, Smith K, Pesaran A, Kim GH. Three dimensional thermal-, electrical-, and electrochemical-coupled model for cylindrical wound large format lithium-ion batteries. J. Power Sources 2013;241(6):20-32.

[12] Mao J, Tiedemann W, Newman J. Simulation of temperature rise in Li-ion cells at very high currents. J. Power Sources 2014;271:444-454.

[13] Sun UK, Monroe CW, Christensen J, Albertus P, Cook D. Thermoelectrochemical simulations of performance and abuse in 50-Ah automotive cells. J. Power Sources 2014;268(3):625-633.

[14] Panchal S, Mathew M, Fraser R, Fowler M. Electrochemical thermal modeling and experimental measurements of 18650 cylindrical lithium-ion battery during discharge cycle for an EV. Appl. Therm. Eng. 2018;135:123-132.

[15] Panchal S, Mathewson S, Fraser R, Culham R, Fowler M. Thermal Management of Lithium-Ion Pouch Cell with Indirect Liquid Cooling using Dual Cold Plates Approach, SAE International Journal of Alternative Powertrains. 2015;4:293-307.

[16] Panchal S, Dincer I, Agelin-Chaab M, Fraser R, Fowler M, Design and simulation of a lithium-ion battery at large C-rates and varying boundary conditions through heat flux distributions. Measurement. 2018;116:382-390,

[17] Wu B, Li Z, Zhang JB. Thermal design optimization of laminated lithium ion battery based on the analytical solution of planar temperature distribution. Scientia Sinica Technologica 2014;11:1154-1172.

[18] Li M, Wang F. Thermal Performance Analysis of the Lithium-Ion Batteries. Parallel and Distributed Computing, Applications and Technologies, PDCAT Proceedings. 2011;483-486.

[19] Kim US, Shin CB, Kim CS. Effect of electrode configuration on the thermal behaviour of a lithium-polymer battery. J. Power Sources 2008;180(2):909-916.

[20]Dong HJ. Numerical modelling of lithium ion battery for predicting thermal behaviour in a cylindrical cell. Curr. Appl. Phys. 2014;14(2):196-205.

[21] Niculuţă MC, Veje C. Analysis of the thermal behavior of a LiFePO4 battery cell. J. Phys. Conf. 2012;39(1):2013.

[22] Xu M, Zhang Z, Jia L, Yang L. Study on electrochemical and heat transfer characteristics of cylindrical lithium-ion power battery during discharge cycle. Proceedings of the CSEE. 2013,33(032): 54-61.

[23] Khan N, Kalair A, Abas N, Haider A. Review of ocean tidal, wave and thermal energy technologies. Renew. Sust. Energ. Rev. 2017;72:590-604.

[24] Li W, Yang L, Ji Y, Xu P. Estimating demand response potential under coupled thermal inertia of building and air-conditioning system. Energ. Buildings. 2019;182:19-29,

[25] Zheng J, Zhou Z, Zhao J, Wang J, Integrated heat and power dispatch truly utilizing thermal inertia of district heating network for wind power integration. Appl. Energ. 2018; 211:865-874,

[26] Fang W, Kwon O J, Wang C Y. Electrochemical-thermal modeling of automotive Li-ion batteries and experimental validation using a three-electrode cell. Int. J. Energy. Res. 2010;34(2):107-115.

[27]Lee KJ, Smith K, Pesaran A.Kim GH. Three dimensional thermal-, electrical-, and 
electrochemical-coupled model for cylindrical wound large format lithium-ion batteries. J. Power Sources. 2013;241:20-32.

[28] Jiang F, Peng P, Sun Y. Thermal analyses of $\mathrm{LiFePO}_{4} /$ graphite battery discharge processes. J. Power Sources. 2013;243:181-194.

[29] Smith K, Wang C Y. Solid-state diffusion limitations on pulse operation of a lithium ion cell for hybrid electric vehicles. J. Power Sources. 2006;161(1):628-639.

[30] Xu M, Zhang Z, Wang X, Jia L, Yang L. Two-dimensional electrochemical-thermal coupled modeling of cylindrical LiFePO4 batteries. J. Power Sources. 2014;256(12):233-243.

[31] COMSOL Multyphisics User’s Guide. Version 5.3a, COMSOL AB, 2017. 